\title{
Changing Lifestyles Towards a Low Carbon Economy: An IPAT Analysis for China
}

\author{
Klaus Hubacek $^{1{ }^{1} *}$, Kuishuang Feng ${ }^{1}$ and Bin Chen ${ }^{2}$ \\ 1 Department of Geography, College Park, University of Maryland, MD 20742, USA; \\ E-Mail:kfeng@umd.edu \\ 2 State Key Joint Laboratory of Environment Simulation and Pollution Control, School of \\ Environment, Beijing Normal University, Beijing 100875, China; E-Mail: chenb@bnu.edu.cn \\ * Author to whom correspondence should be addressed; E-Mail: hubacek@umd.edu; \\ Tel.: +1-301-405-4567; Fax: +1-301-314-9299.
}

Received: 20 October 2011; in revised form: 9 December 2011 / Accepted: 20 December 2011 / Published: 27 December 2011

\begin{abstract}
China has achieved notable success in developing its economy with approximate 10 percent average annual GDP growth over the last two decades. At the same time, energy consumption and $\mathrm{CO}_{2}$ emissions almost doubled every five years, which led China to be the world top emitter in 2007. In response, China's government has put forward a carbon mitigation target of $40 \%-45 \%$ reduction of $\mathrm{CO}_{2}$ emission intensity by 2020 . To better understand the potential for success or failure of such a policy, it is essential to assess different driving forces such as population, lifestyle and technology and their associated $\mathrm{CO}_{2}$ emissions. This study confirms that increase of affluence has been the main driving force for China's $\mathrm{CO}_{2}$ emissions since the late 1970s, which outweighs reductions achieved through technical progress. Meanwhile, the contribution of population growth to $\mathrm{CO}_{2}$ emissions was relatively small. We also found a huge disparity between urban and rural households in terms of changes of lifestyle and consumption patterns. Lifestyles in urban China are beginning to resemble Western lifestyles, and approaching their level of $\mathrm{CO}_{2}$ emissions. Therefore, in addition to the apparent inefficiencies in terms of production technologies there is also a lot of room for improvement on the consumption side especially in interaction of current infrastructure investments and future consumption.
\end{abstract}

Keywords: IPAT; lifestyle; technology; energy consumption; $\mathrm{CO}_{2}$ emissions; China 


\section{Introduction}

China as the world's most populous country has achieved notable success in developing its economy, with approximate 10 percent average annual GDP growth over the last two decades [1-3]. Large sectors of the population have been experiencing a transition from "poverty" to "adequate food and clothing"; today, growing parts of the population are getting closer to "well to do" lifestyles [3]. However, the rapid growth of the economy has not only lead to dramatic changes of wealth and people's lifestyles, but has also caused a huge amount of resource and energy consumption and associated emissions creating serious environmental problems on local, regional and global scales [4-6]. Between 1990 and 2010 China's total energy consumption has grown 5.8\% annually from 863 Million tonnes of oil equivalent (Mtoe) to $2634 \mathrm{Mtoe}$, and $\mathrm{CO}_{2}$ emissions grew by 2.5 times from 2269 million metric tons (MMT) to $8262 \mathrm{MMT}$ [7]. In 2006, China has become the largest $\mathrm{CO}_{2}$ emitter in the world, surpassing the US by an estimated $8 \%$ [8]. In response to the increasing pressure from the international community at the COP15 in Copenhagen China put forward a climate change mitigation target of $40 \%-45 \%$ reduction of $\mathrm{CO}_{2}$ emission intensity by 2020 , increasing the share of non-fossil fuels in primary energy consumption to around $15 \%$ by 2020 ; and in addition increasing forest coverage by 40 million hectares and forest stock volume by 1.3 billion cubic meters by 2020 from the 2005 levels [9]. Moreover, Chinese government published China's Pathway Towards a Low Carbon Economy for 2050 where technology will be still playing the major role on the reduction of carbon emissions [10]. However, apart from technology, there are also other factors playing a significant role in the creation of $\mathrm{CO}_{2}$ emissions that need to be taken into account.

\section{Changes of Lifestyle, Population and Technology}

In this study, we employ the IPAT framework to examine the contribution to $\mathrm{CO}_{2}$ emissions $(I)$ of Population growth $(P)$, Affluence $(A)$ (representing different lifestyles and consumption patterns) and $\mathrm{CO}_{2}$ intensity $(T)$ representing Technology:

$$
I=P * A * T
$$

where $P$ denotes population; $A$ denotes per capita living expenditure in Yuan; $T$ denotes $\mathrm{CO}_{2}$ emissions per unit of output (emission intensity). The IPAT identity has been regarded as an easily understandable, widely utilized framework for analyzing the driving forces of environmental change (e.g., [11-17]). It allows to explicitly identify the relationship between the driving forces and environmental impacts [18], but has also been criticized for assuming a proportional relationship between factors and environmental indicators [18]. IPCC (2001) discussed the IPAT and the Kaya identity and their application to future emissions scenarios covering a wide range of the main driving forces from demographic to technological and economic developments [19]. Ang and others have gathered a substantial amount of literature on index decomposition analysis, upon which the IPAT model is based, for energy use and environmental emissions (e.g., [20-22]). In recent years, much research has been done to further develop the IPAT framework by incorporating more factors into the equation (e.g., [23]) through further disaggregating technology (T). Rosa and Dietz [24] reformulated the IPAT equation into a stochastic model, referred to as STIRPAT for Stochastic Impacts by Regression on Population, Affluence and Technology, which allows assessing non-proportional 
relationships among the drivers; this model had been applied to analyze the effects of driving forces on energy consumption and $\mathrm{CO}_{2}$ emissions by York et al. [18].

In the following, we analyze the contribution of three major driving forces (Population, Affluence and $\mathrm{CO}_{2}$ intensity) to $\mathrm{CO}_{2}$ emissions in China from the inception of the open door policy in 1978 to 2008. After the economic reforms in 1978, China experienced an unprecedented growth of its economy. During the economic reform period China not only achieved rapid improvement of living standards, but also showed a comprehensive modernization of large sectors of the economy and fast improvement of technologies [1].

Table 1 shows that $\mathrm{CO}_{2}$ emissions in China increased by 49\% from 1979 to 1988; then the growth rate slightly slowed down to $44 \%$ during the next decade and increased again with a $88 \%$ growth rate during the last decade. For these three decades, the results show that for China affluence had the highest growth rates, and thus has been the major contributor to China's $\mathrm{CO}_{2}$ emissions. Although there was much improvement in emissions intensity with $44 \%$ and $29 \%$ reduction in the first two decades and another 30\% reduction in the last decade, the carbon savings through improvement of carbon intensity was outweighed by fast growth in affluence levels more than doubling in the first and last decade of the study period. The population growth rate has decreased from 14\% between 1979 and 1988 to $6 \%$ between 1999 and 2008; thus, the contribution of population to $\mathrm{CO}_{2}$ emissions was also relatively small.

Table 1. $\mathrm{CO}_{2}$ emissions and driving forces in China (growth in \%).

\begin{tabular}{ccccc}
\hline Years & I & P & A & T \\
\hline $1979-1988$ & 49 & 14 & 136 & -44 \\
$1989-1998$ & 44 & 11 & 85 & -29 \\
$1999-2008$ & 88 & 6 & 154 & -30 \\
\hline
\end{tabular}

Notes: $\mathrm{CO}_{2}=$ Population* (GDP /Population)* $\left(\mathrm{CO}_{2} / \mathrm{GDP}\right)$, where $\mathrm{CO}_{2}$ is the impact (I), Population is $\mathrm{P}, \mathrm{GDP} / \mathrm{Population}$ represents affluence (A), and $\mathrm{CO}_{2} / \mathrm{GDP}$ represents $\mathrm{CO}_{2}$ intensity ( $\mathrm{T}$; emissions per unit of output).

There is a huge disparity between urban and rural China. To further analyze the driving forces distinguishing rural and urban areas, we use living expenditure as proxy for affluence as provided by the statistical yearbooks [25]; the results are presented in Tables 2 and 3. We can see that $\mathrm{CO}_{2}$ emissions in urban and rural area increased at different rates over the observed time period. The results show that the urban population in China increased rapidly whereas the rural population even declined between 1999 and 2008; this was due to the fast growth of urbanization and high demand for labor in urban areas combined with a more liberal handling of the family registration system that had previously restricted internal migration. For the influencing factor affluence, i.e., A, there is also a disparity in growth rates between urban and rural area, as shown in Tables 2 and 3, the growth rate of affluence in rural China is much higher than that in urban areas. In order to better understand how people's lifestyle changes drive the growth in $\mathrm{CO}_{2}$ emissions, we further describe trends in the main household consumption items that account for changes in energy consumption in urban and rural China. Table 3 also shows an increase in $\mathrm{CO}_{2}$ emission intensity in rural China from 1999 to 2008. This might be due to the growth of mechanization in agricultural production activities and increasing motorization of rural households, e.g., there was a fast increase in the number of motorcycles [26]. 
Table 2. $\mathrm{CO}_{2}$ emissions and driving forces in urban China (growth in \%).

\begin{tabular}{ccccc}
\hline Years & I & P & A & T \\
\hline $1979-1988$ & 89 & 52 & 38 & -25 \\
$1989-1998$ & 64 & 43 & 73 & -24 \\
$1999-2008$ & 102 & 31 & 133 & -31 \\
\hline
\end{tabular}

Table 3. $\mathrm{CO}_{2}$ emissions and driving forces in rural China (growth in \%).

\begin{tabular}{ccccc}
\hline Years & I & P & A & T \\
\hline $1979-1988$ & 27 & 5 & 161 & -45 \\
$1989-1998$ & 11 & 0 & 107 & -30 \\
$1999-2008$ & 53 & -8 & 166 & 22 \\
\hline
\end{tabular}

\section{Changing Energy Consumption in China}

The significant economic and lifestyle changes that have been taking place in China, have led the Chinese to require more and better quality of energy. People consume energy for lighting, cooking and other daily uses. But many also aspire to a "higher-quality life" by purchasing fashionable goods and services but also amenities that are standard in rich countries, such as air conditioning and other modern electrical household appliances, as well as services such as education, health or leisure activities. All these products and services consume energy during their production processes and usage. Domestic energy production cannot meet anymore the rapid increase of consumption requirements on both domestic and industrial usage; hence, China has become a net energy importer in 1993. China has been speeding up exploration and development of energy sources (at home as well as abroad, e.g., in Sudan and Nigeria) to support its fast growing economy. In the following, we show changing consumption patterns exemplified on three important product categories that are indicative of some of the ongoing trends and lifestyle changes in China.

\subsection{Housing}

The outstanding increase of expenditure on housing shows people's willingness to improve their immediate living conditions. The average per capita living space of rural households expanded from 8.1 to $32.4 \mathrm{~m}^{2}$ between 1978 and 2008 [26,27]. Many rural households rebuilt and extended their bungalows by using building materials such as concrete bricks and tiles instead of marl and wood. In urban China, the problem of housing shortage was much more serious than in rural areas. The per capita net living space for urban residents was only $3.6 \mathrm{~m}^{2}$ prior to 1978 , mainly because of restrictions on private house ownership [28]. In the early 1980s, the Housing Reform Policy had been introduced to solve the problems of urban housing shortages and poor housing conditions. This policy encouraged commercialization of the housing sector and private ownership allowing people to buy their own apartment. Meanwhile, the government, state-owned enterprises, domestic private companies and overseas developers invested significant funds into the development of urban housing [28]. It is estimated that between 1979 and 2008 the total investment in housing increased from $6.74 \%$ to $10.38 \%$ of total GDP [26]. As a result, city dwellers started to move from previously tiny bungalows or apartments to new multi-story apartment blocks; thus effectively increasing per capita net living space. 
People's requirements on housing were one of the major reasons that boosted the development of the construction sector. Directly associated with this was the amount of energy consumption in the construction sector which increased from 7.89 Mtce in 1980 to 38.12 Mtce in 2008 [26].

\subsection{Household Appliances}

These more spacious living places allow consumers to buy and store more household appliances and other durable goods (See Tables 4 and 5). For example, since the 1980s, urban residents spent increasing amounts on large durable furniture (e.g., wardrobes, beds and sofas). Also in the late 1980s and 1990s, the connection of a larger number of households to the electrical grid enabled and helped increase the sales for household electrical appliances. For example, purchases of refrigerators and color TVs in urban areas have been 2.25 times larger in 2008 than in 1990. Similarly, in rural areas, more reliable electricity supply makes it possible for many rural families to purchase home appliances, such as color TVs, washing machines, refrigerators and even air conditioners can be found among wealthier rural families [29]. Color TVs have already covered over half of rural households, and some urban households have more than one color TV [26], and other categories of electric appliances have been rapidly spreading throughout China. Another example is air conditioners, previously a sign of the wealthy, which increased significantly to about 30 sets per 100 households by 2000, and almost trebled between 2000 and 2008. The use of IT appliances such as computers and mobile phones also has increased rapidly in Chinese households. In 2000, computers and mobile phones could be hardly found in Chinese families. Today, more than half of urban households have computers, and most of households have more than one mobile phone. In fact, mobile phones have become a very common communication tool in rural China [26]. The popularization of household electronics enormously boosted the household appliance production. The electronic industry has become the largest industry in China, which contributed about $8-10 \%$ of GDP and $30 \%$ of exports in 2000 [27]. The energy consumed in the manufactory industries is therefore experienced a rapid growth during the studied period.

Table 4. Durable goods per 100 families for urban residents in China.

\begin{tabular}{lccccccc}
\hline \multicolumn{1}{c}{ Year } & $\mathbf{1 9 7 8}$ & $\mathbf{1 9 8 5}$ & $\mathbf{1 9 9 0}$ & $\mathbf{1 9 9 5}$ & $\mathbf{2 0 0 0}$ & $\mathbf{2 0 0 5}$ & $\mathbf{2 0 0 9}$ \\
\hline Color TV & - & 17.21 & 59.04 & 89.79 & 116.60 & 134.80 & 135.65 \\
Washing machine & - & 48.29 & 78.41 & 88.97 & 90.50 & 95.51 & 96.01 \\
Refrigerator & - & 6.58 & 42.33 & 66.22 & 80.10 & 90.72 & 95.35 \\
Air conditioner & - & - & 0.34 & 8.09 & 30.80 & 80.67 & 106.84 \\
Water heater & - & - & - & 30.05 & 49.10 & 72.65 & 83.39 \\
PC & - & - & - & - & 9.70 & 41.52 & 65.74 \\
Car & - & - & - & - & 0.50 & 3.37 & 10.89 \\
\hline
\end{tabular}

Data source: China Statistical Yearbooks 1985-2010 [30].

Table 5. Durable goods per 100 families for rural residents in China.

\begin{tabular}{lccccccc}
\hline \multicolumn{1}{c}{ Year } & $\mathbf{1 9 7 8}$ & $\mathbf{1 9 8 5}$ & $\mathbf{1 9 9 0}$ & $\mathbf{1 9 9 5}$ & $\mathbf{2 0 0 0}$ & $\mathbf{2 0 0 5}$ & $\mathbf{2 0 0 9}$ \\
\hline Color TV & - & - & 4.72 & 16.92 & 48.74 & 84.08 & 108.94 \\
Washing machine & - & 1.9 & 9.12 & 16.90 & 28.58 & 40.20 & 53.14 \\
Refrigerator & - & 0.06 & 1.22 & 5.15 & 12.31 & 20.10 & 37.11 \\
\hline
\end{tabular}


Table 5. Cont.

\begin{tabular}{lccccccc}
\hline \multicolumn{1}{c}{ Year } & $\mathbf{1 9 7 8}$ & $\mathbf{1 9 8 5}$ & $\mathbf{1 9 9 0}$ & $\mathbf{1 9 9 5}$ & $\mathbf{2 0 0 0}$ & $\mathbf{2 0 0 5}$ & $\mathbf{2 0 0 9}$ \\
\hline Air conditioner & - & - & - & 0.18 & 1.32 & 6.40 & 12.23 \\
PC & - & - & - & - & 0.47 & 2.10 & 7.46 \\
Motorcycle & - & - & 0.89 & 4.91 & 21.94 & 40.70 & 56.64 \\
\hline
\end{tabular}

Data source: China Statistical Yearbooks 1985-2010 [30].

\subsection{Residential Energy Consumption}

There are huge differences in terms of residential energy consumption between rural and urban households with regards to quality and quantity. Until recently, non-commercial energy sources such as stalks and firewood still dominated rural residential energy consumption patterns and contributed approximately $85 \%$ of rural residential energy in 1980 [31]. In the production sector, wood fuel is mainly used but does not account for a large proportion of local traditional production, such as tea and food processing and ceramic firing. The heavy use of biomass energy contributed to degradation of cultivated land and destruction of forest resources. Since the policy of biomass energy conservation and forestation was established in the mid-1990s, the absolute amount of biomass energy consumption has fallen from 250 Mtce in 1995 to around 200 Mtce in 2000. However, as a large agricultural country, although China is accused of low conversion efficiency of biomass energy combustion, biomass energy is and will remain a significant source of energy for much of China's rural population, especially in poor areas. Therefore, it is interesting to point out that the commercial energy for rural residential should be used to gradually replace the low-efficiency biomass energy and become the major energy source in the future. Also household consumption of coal showed a declining trend after 1988 due to the introduction of fuel-saving stoves. By the end of 1997, the fuel-saving stoves had been installed in 180 million rural households, which accounted for $89 \%$ of total rural households [32].

Urban household energy consumption has also undergone significant changes. In terms of heating, most urban areas still keep the traditional way of heating by burning coal. The increase of per capita net living space is likely to result in more coal being consumed. However, the previous type of individual heating has been switched to large-scale central heating as people moved from bungalows to apartment blocks, which effectively enhanced energy efficiency. Furthermore, many richer cites (e.g., Beijing) have installed the "consumer control system" of heat supply to allow heat supply to best match demand (the "consumer control system" refers to charging fees based on the real consumption of each household. The advantage of this approach is that it could reduce the heat consumption by indoor temperature adjustment). In addition, the government provides LPG (liquefied petroleum gas) or gas pipelines for people's daily cooking instead of traditional cooking by burning coal, to reduce urban coal consumption and associated pollution. Per capita coal consumption for urban residential use substantially declined from $348.5 \mathrm{~kg}$ /year in 1985 to $88.2 \mathrm{~kg} /$ year in 1999 . The main difference to energy consumption of 20 to 30 years ago is the difference in electricity consumption. Due to the outstanding growth of household electrical appliances for urban households, the per capita residential electricity consumption increased more than seven times during 1985-2008 (306 kWh in 2008). Electricity became the dominant source of energy in most Chinese cities, accounting for $59 \%$ of the total household energy consumption [26]. 
In the rural areas, total energy consumption has increased substantially from 307.19 Mtce in 1979 to 977.14 Mtce in 2007, more than a tripling with an annual growth of $4.2 \%$. Correspondingly, the per capita energy consumption has increased at a steady rate of $4.5 \%$ from $388.78 \mathrm{kgce}$ in 1979 to $1343.14 \mathrm{kgce}$ in 2007. There are two types of energy users in rural China: consumption for production of goods and services and residential use. The proportion of residential energy in total energy use has declined from $83.1 \%$ in 1979 to $55.8 \%$ in 2007 , but still remains at over half of the total energy consumption indicating a relatively low level of agricultural mechanization and industrial activities [33]. In fact, the absolute amount of energy consumed by households has increased from 255.4 Mtce to 545.2 Mtce during the concerned period. The level of electricity consumption is an essential index usually adopted to reflect the economic development and energy structure in rural areas. Since the 1980s, with the development of rural electrification by promotion of building electrical networks and small hydro plants (less than $50 \mathrm{MW}$ ), electricity consumption has increased rapidly both for production and for household use. The total amount reached $2.52 \times 10^{5} \mathrm{GWh}$, of which $0.86 \times 10^{5} \mathrm{GWh}$ was for residential use in 2007. Apart from small hydropower, in remote areas away from grid-based electricity service, there are still about $1.06 \times 10^{5}$ wind mills with installed capacity of $12.4 \mathrm{MW}$ and annual output of $39.3 \mathrm{GWh}$ in 2005 [34]. However, the amount of wind mills decreased dramatically during the tenth 5-year plan (2001-2005), possibly due to unstable utilization and high maintenance cost. During the eleventh 5-year plan, however, the amount of wind mills increased again to solve electricity shortage in rural areas. In 2008, the installed capacity of wind mills in rural areas has reached $73 \times \mathrm{MW}$, which is six times that in 2005 [33]. By 2010, the total installed Chinese wind capacity has exceeded the US to become the World's largest country in terms of wind capacity according to the Global Wind Energy Council report. The total installed capacity reached 42 GW [35].

\section{Conclusions and Outlook}

Our case studies on energy use have shown that the rate of efficiency gains in production was not able to keep up with the growth in emissions due to growth in final consumption and associated production processes. More and more people "move up" the consumption ladder as a result of increasing income levels, increasing availability of infrastructure and higher availability of products and services even in remote rural locations. With expansion of the national electricity grid and improvement in living conditions and available space have naturally enabled acquisition of electronic appliances and other consumption goods. Similarly, improved transport infrastructure, i.e., roads and airports, together with increasing levels of available income will lead to more car and air miles. A trajectory of further increase in consumption and pollution levels compensating gains in efficiency levels can easily be foreseen given current trajectories [1]. We will thus probably observe a further move to services, a continuation of investments in housing, machinery and infrastructure but eventually a decline in the share of capital investments as infrastructure and other capital goods reach Western levels [6]. For example, the China Council for International Cooperation on Environment and Development (CCICED) projected that China's absolute emissions would start decreasing by 2050 under the business-as-usual scenario but even under the low carbon scenario under a low growth rate absolute emissions would not start declining before 2030 [10]. However, this more "optimistic" scenario requires large investments in low carbon infrastructure and technology. 
In addition to the apparent inefficiencies in terms of production technologies there is also a lot of room for improvement on the consumer side, especially also with regards to the interaction of infrastructure and consumption. This might be even easier to achieve for developing countries. Wasteful infrastructure, institutions and habits have not been developed to the same extent as in the resource addictive "North". Similarly, technological and institutional leapfrogging could help the "under-consumers" to achieve higher level of consumption. From technological and energy efficiency points of view much in this direction is already happening in some of the more advantaged areas such as the coastal areas in China driven by high levels of foreign direct investment and improved efficiency rates. With regards to the consumption side, this is much more difficult to achieve in developing or transition countries trying to emulate Western lifestyles. Influencing consumers towards "greener lifestyles" is difficult given the huge differences in money and resources that are spent on marketing for consumption items in comparison to the miniscule amounts available for, e.g., recycling campaigns, a problem shared by public agencies and non-governmental organizations in developed and developing countries alike. Moreover, future expenditures and consumer behavior depend to a large extent on the infrastructure that is built today. Consumers' choices are bound by the availability of alternatives (such as public transport). Thus, the trajectory of future emissions needs to be addressed by the infrastructure choices of today [3]. In terms of the composition of the major consumption items there are little alternatives in sight as Chinese consumers try to emulate Western lifestyles and thus, inadvertently, Western levels of emissions. This paper emphasizes the need to guide people's lifestyles towards more sustainable ways of living; this is also true for a developing country such as China, which is home to $22 \%$ of the world population and a growing middle class, and which is on a fast track to modernization.

\section{References}

1. Feng, K.; Hubacek, K.; Guan, D. Lifestyles, technology and $\mathrm{CO}_{2}$ emissions in China: A regional comparative analysis. Ecol. Econ. 2009, 69, 145-154.

2. Guan, D.; Peters, G.P.; Weber, C.L.; Hubacek, K. Journey to world top emitter: An analysis of the driving forces of China's recent $\mathrm{CO}_{2}$ emissions surge. Geophys. Res. Lett. 2009, 36, 1-5.

3. Hubacek, K.; Guan, D.; Barua, A. Changing lifestyles and consumption patterns in developing countries: A scenario analysis for china and india. Futures 2007, 39, 1084-1096.

4. Liu, J.; Daily, G.C.; Ehrlich, P.R.; Luck, G.W. Effects of household dynamics on resource consumption and biodiversity. Nature 2003, 421, 530-533.

5. Liu, J.; Diamond, J. China's environment in a globalizing world. Nature 2005, 435, 1179-1186.

6. Peters, G.P.; Weber, C.L.; Guan, D.; Hubacek, K. China's growing $\mathrm{CO}_{2}$ emissions: A race between increasing consumption and efficiency gains. Environ. Sci. Technol. 2007, 41, 5939-5944.

7. EIA. International Energy Statistics; US Energy Information Administration: Washington, DC, USA, 2011.

8. MNP. China Now No. 1 in $\mathrm{CO}_{2}$ Emissions; USA in Second Position; Netherlands Environmental Assessment Agency: Wexford, Ireland, 2007.

9. Su, W. China's Pledge in Cop15; Department of Climate Change, National Development \& Reform Commission of China: Beijing, China, 2010. Available online: http://unfccc.int/files/meetings/cop_15/ copenhagen_accord/application/pdf/chinacphaccord_app2.pdf(accessed on 15 December 2011). 
10. CCICED. China's Pathway Towards a Low Carbon Economy; China Council for International Cooperation on Environment and Development: Beijing, China, 2009.

11. Chertow, R.M. The ipat equation: Changing views of technology and environmental impact. J. Ind. Ecol. 2001, 4, 13-28.

12. Dietz, T.; Rosa, E.A. Rethinking the environmental impacts of population, affluence and technology. Hum. Ecol. Rev. 1994, 1, 277-300.

13. Dietz, T.; Rosa, E.A. Effects of population and affluence on $\mathrm{CO}_{2}$ emissions. Proc. Natl. Acad. Sci. USA 1997, 94, 175-179.

14. Harrison, P. The Third Revolution: Penguin: London, UK, 1993.

15. Hubacek, K.; Guan, D.; Barua, A. Changing lifestyles and consumption patterns in developing countries: A scenario analysis for china and india. Futures 2007, 39, 1084-1096.

16. Raskin, P.D. Methods for estimating the population contribution to environmental change. Ecol. Econ. 1995, 15, 225-233.

17. York, R.; Rosa, E.A.; Dietz, T. Bridging environmental science with environmental policy: Plasticity of population, affluence, and technology. Soc. Sci. Q. 2002, 83, 18-34.

18. York, R.; Rosa, E.A.; Dietz, T. Stirpat, ipat and impact: Analytic tools for unpacking the driving forces of environmental impacts. Ecol. Econ. 2003, 46, 351-365.

19. Intergovernmental Panel on Climate Change (IPCC). IPCC Special Report on Emissions Scenarios; 2001. Available online: http://www.grida.no/publications/other/ipcc_sr/?src=/climate/ ipcc/emission/ (accessed on 15 December 2011).

20. Ang, B.W.; Liu, F.L. A new energy decomposition method: Perfect in decomposition and consistent in aggregation. Energy 2001, 26, 537-548.

21. Ang, B.W.; Liu, F.L.; Chung, H.-S. A gereralized fisher index approach to energy decompostion analysis. Energy Econ. 2004, 26, 757-763.

22. Ang, B.W.; Zhang, F.Q. A survey of index decomposition analysis in energy and environmental studies. Energy 2000, 25, 1149-1176.

23. Waggoner, P.E.; Ausubel, J.H. A framework for sustainability science: A renovated ipat identity. Proc. Natl. Acad. Sci. USA 2002, 99, 7860-7865.

24. Rosa, E.A.; Dietz, T. Climate change and society: Speculation, construction and scientific investigation. Int. Sociol. 1998, 13, 421-455.

25. National Statistical Bureau of China. China Provincial Statistics Yearbook 1985-2008; National Statistical Bureau of China: Beijing, China, 1985-2008.

26. State Statistical Bureau of China. China Statistical Yearbook 2008; State Statistical Publishing House: Beijing, China, 2009.

27. State Statistical Bureau of China. China Statistical Yearbook 2001; State Statistical Publishing House: Beijing, China, 2002.

28. Lin, J.Y. The household responsibility system in china's agricultural reform: A theoretical and empirical study. Econ. Dev. Cult. Change 1998, 36, 199-224.

29. Wang, X.; Feng, Z. Rural household energy consumption with the economic development in china: Stages and characteristic indices. Energy Policy 2001, 29, 1391-1397.

30. State Statistical Bureau of China. China Statistical Yearbook 1985-2010; State Statistical Publishing House: Beijing, China, 1985-2010. 
31. Zhou, F. Study on Long Term Energy Development Strategies of China. China Planning Press: Beijing, China, 1999.

32. Wang, M. Fuel-saving stoves in china. Wood Energy New 1998, 3, 9-10.

33. Zhang, L.; Yang, Z.; Chen, B.; Chen, G. Rural energy in china: Pattern and policy. Renew. Energy 2009, 34, 2813-2823.

34. Li, Z.; Yue, Y.; Chen, K. Statistical analysis on renewable energy during tenth five-year plan period in rural china. China Construct. Solar Renew. Energy Sour. 2006, 8, 60-64.

35. Global Wind Energy Council Total installed capacity China. Available online: http://www.gwec.net/index.php?id=125 (accessed on 15 December 2011).

(C) 2012 by the authors; licensee MDPI, Basel, Switzerland. This article is an open access article distributed under the terms and conditions of the Creative Commons Attribution license (http://creativecommons.org/licenses/by/3.0/). 